\title{
Characterization of Ubrogepant: A Potent and Selective Antagonist of the Human Calcitonin Gene-Related Peptide Receptors
}

\author{
Eric Moore, Mark E. Fraley, lan M. Bell, Christopher S. Burgey, Rebecca B. White, \\ Chi-Chung Li, Christopher P. Regan, Andrew Danziger, Maria Stranieri Michener, \\ Eric Hostetler, Pradeep Banerjee, and Christopher Salvatore \\ Merck Sharp \& Dohme Corp., a subsidiary of Merck \& Co., Inc., Kenilworth, New Jersey (E.M., M.E.F., I.M.B., C.S.B., R.B.W., \\ C.-C.L., C.P.R., A.D., M.S.M., E.H., C.S.) and Allergan plc, Madison, New Jersey (P.B.)
}

Received August 12, 2019; accepted November 18, 2019

\begin{abstract}
A growing body of evidence has implicated the calcitonin gene-related peptide (CGRP) receptors in migraine pathophysiology. With the approval of monoclonal antibodies targeting CGRP or the CGRP receptor, the inhibition of CGRP-mediated signaling emerged as a promising approach for preventive treatments of migraine in adults. Recently, small-molecule antiCGRP treatments have shown efficacy for treating migraine. The current studies aimed to characterize the pharmacologic properties of ubrogepant, an orally bioavailable CGRP receptor antagonist for the acute treatment of migraine. In a series of ligand-binding assays, ubrogepant exhibited a high binding affinity for native $\left(K_{\mathrm{i}}=0.067 \mathrm{nM}\right)$ and cloned human $\left(K_{\mathrm{i}}=\right.$ $0.070 \mathrm{nM})$ and rhesus CGRP receptors $\left(K_{\mathrm{i}}=0.079 \mathrm{nM}\right)$, with relatively lower affinities for CGRP receptors from rat, mouse, rabbit, and dog. In functional assays, ubrogepant potently blocked human $\alpha$-CGRP-stimulated cAMP response $\left(\mathrm{IC}_{50}\right.$ of $0.08 \mathrm{nM}$ ) and exhibited highly selective antagonist activity for the CGRP receptor compared with other members of the human calcitonin receptor family. Furthermore, the in vivo CGRP
\end{abstract}

receptor antagonist activity of ubrogepant was evaluated in a pharmacodynamic model of capsaicin-induced dermal vasodilation (CIDV) in rhesus monkeys and humans. Results demonstrated that ubrogepant produced concentration-dependent inhibition of CIDV with a mean $\mathrm{EC}_{50}$ of 3.2 and $2.6 \mathrm{nM}$ in rhesus monkeys and humans, respectively. Brain penetration studies with ubrogepant in monkeys showed a cerebrospinal fluid:plasma ratio of 0.03 and low CGRP receptor occupancy. In summary, ubrogepant is a competitive antagonist with high affinity, potency, and selectivity for the human CGRP receptor.

\section{SIGNIFICANCE STATEMENT}

Ubrogepant is a potent, selective, orally delivered, smallmolecule competitive antagonist of the human CGRP. In vivo studies using a pharmacodynamic model of CIDV in rhesus monkeys and humans demonstrated that ubrogepant produced concentration-dependent inhibition of CIDV, indicating a predictable pharmacokinetic-pharmacodynamic relationship.

\section{Introduction}

Migraine is a highly prevalent, chronic neurologic disease and the leading cause of disability in people aged 15-49 years (Burch et al., 2018; Steiner et al., 2018). Commonly used acute

This work was supported by Allergan plc, Dublin, Ireland.

This work was previously presented in abstract form: Moore E, Burgey CS, Fraley M, Danziger A, Regan C, Li CC, White RB, Banerjee P, Salvatore C (2019). Characterization of ubrogepant: a potent and selective antagonist of the human calcitonin gene-related peptide receptor. Neurology. 92 Suppl 15:P4.10021.

Disclosures: E.M., M.E.F., I.M.B., C.S.B., R.B.W., C.-C.L., C.P.R., A.D., M.S.M., E.H., and C.S. are employees of Merck Sharp \& Dohme Corp. a subsidiary of Merck \& Co., Inc.,, (Kenilworth, NJ,) and own/hold stock/stock options of Merck \& Co., Inc., (Kenilworth, NJ.) P.B. is an employee of Allergan plc (Madison, NJ) and owns stock in the company.

https://doi.org/10.1124/jpet.119.261065.

S This article has supplemental material available at jpet.aspetjournals.org. treatments for migraine attacks include triptans, opioids, nonsteroidal anti-inflammatory drugs, ergotamine derivatives, barbiturates, and combination analgesics (Holland et al., 2013; Martelletti, 2017). However, the utility of these treatments is limited by low levels of adherence and patient satisfaction stemming largely from inadequate efficacy and poor tolerability (Holland et al., 2013; Lipton et al., 2013; Messali et al., 2014; Serrano et al., 2015; Martelletti, 2017). As a result, many people with migraine discontinue acute treatments and may experience uncontrolled attacks or migraine disease progression (Holland et al., 2013; May and Schulte, 2016; Thorlund et al., 2016).

Theories explaining the pathophysiology of migraine have shifted away from a purely vascular disease model toward a neurogenic theory focusing on the neuropeptide calcitonin gene-related peptide (CGRP) (Humphrey, 2007; Eftekhari

ABBREVIATIONS: AM, adrenomedullin; AMY, amylin; cAMP, cyclic adenosine monophosphate; CGRP, calcitonin gene-related peptide; CIDV, capsaicin-induced dermal vasodilation; CLR, calcitonin receptor-like receptor; CNS, central nervous system; CSF, cerebrospinal fluid; CT, calcitonin; CTR, calcitonin receptor; HEK293, human embryonic kidney-derived; hERG, human ether-a-go-go-related gene; PD, pharmacodynamic; PET, positron emission tomography; PK, pharmacokinetic; RAMP, receptor activity modifying protein. 
and Edvinsson, 2010; Moore and Salvatore, 2012; GonzalezHernandez et al., 2018). CGRP is a 37-amino acid peptide and potent vasodilator present at elevated levels in the trigeminovascular system during migraine attacks (Goadsby et al., 1990; Russell et al., 2014). The calcitonin family of peptides includes calcitonin (CT), amylin (AMY), adrenomedullin (AM), and CGRP (Poyner et al., 2002). The CGRP receptor is made up of a CT receptor (CTR)-like receptor (CLR) and receptor activity modifying protein 1 (RAMP1) (Eftekhari and Edvinsson, 2010; Kiriyama and Nochi, 2018). Distribution of CLR and RAMP1 has been mapped to the cytoplasm of trigeminal neurons, at peripheral sites on the intracranial vasculature (in the smooth muscle cells), in the dura matter (both vascular and avascular localization), and in the brainstem (Edvinsson and Warfvinge, 2019). The AMY receptors are a complex of

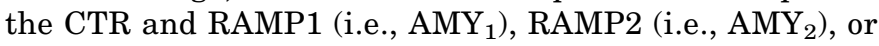
RAMP3 (i.e., $\mathrm{AMY}_{3}$ ) that have a high affinity for AMY. The $\mathrm{AMY}_{1}$ receptor also binds CGRP, is found in the trigeminal ganglion, and has been implicated in animal models of pain signaling; however, its role in migraine pathophysiology remains to be determined (Gebre-Medhin et al., 1998; Poyner et al., 2002; Walker et al., 2015; Kiriyama and Nochi, 2018; Edvinsson and Warfvinge, 2019). The AM receptors are a complex of the CLR and RAMP2 $\left(\mathrm{AM}_{1}\right)$ and RAMP3 $\left(\mathrm{AM}_{2}\right)$, which have a high affinity for AM (Kiriyama and Nochi, 2018). The function of AM receptors in migraine is unknown, and, unlike with CGRP, intravenous infusion of AM was not found to precipitate migraine pain (Petersen et al., 2009).

A substantial amount of scientific data implicates the CGRP pathway in the underlying physiologic mechanisms associated with migraine (Goadsby et al., 1990; Lassen et al., 2002; Edvinsson, 2015). Furthermore, previously investigated small-molecule CGRP receptor antagonists have demonstrated efficacy in the treatment of migraine, although development was eventually halted because of safety concerns (Hewitt et al., 2011; Ho et al., 2014; Hargreaves and Olesen, 2019). The clinical success of monoclonal antibodies targeting CGRP also provides support for the CGRP receptors as a promising therapeutic target for migraine (Dodick, 2019).

Ubrogepant is an orally bioavailable, potent, and specific CGRP receptor antagonist that was approved in December 2019 for the acute treatment of migraine in adults with or without aura. Ubrogepant is chemically distinct from previous small-molecule CGRP receptor antagonists (Ubrelvy, 2019) (Yasuda et al., 2017). In clinical trials, ubrogepant provided substantial pain relief and return to function, and was generally well tolerated. The objective of the present communication is to describe and characterize the pharmacologic profile of ubrogepant.

\section{Materials and Methods}

\section{In Vitro Pharmacology}

Binding Affinity. To assess ubrogepant's affinity and selectivity for CGRP and $\mathrm{AM}$ receptors, cloned CGRP and $\mathrm{AM}_{2}$ receptors were stably expressed in human embryonic kidney-derived (HEK293) cells. To assess ubrogepant's affinity for $\mathrm{AMY}_{1}$ receptors, cloned $\mathrm{AMY}_{1}$ receptors were transiently expressed in monkey kidney-derived cells by transfection with equal amounts of CTR and RAMP1 to monitor selectivity of ubrogepant for this receptor.

For receptor binding assays, membrane fractions were isolated from cell homogenates from the HEK293 or monkey kidney-derived cells or homogenates of cerebellum isolated from rhesus, rat, mouse, rabbit, and dog. Human $\left[{ }^{125} \mathrm{I}\right] \mathrm{CGRP}$ and $\left[{ }^{125} \mathrm{I}\right] \mathrm{AM}$ and rat $\left[{ }^{125} \mathrm{I}\right] \mathrm{AMY}$ were used as radioligands for the binding assays. Nonspecific binding was determined by $10 \mu \mathrm{M}$ MK-3207 (Salvatore et al., 2010), a structurally distinct CGRP receptor antagonist. The tests were conducted in $1 \mathrm{ml}$ of binding buffer (10 mM HEPES, $\mathrm{pH} 7.4,5 \mathrm{mM} \mathrm{MgCl}$, and $0.2 \%$ bovine serum albumin) for 3 hours at room temperature containing $10 \mathrm{pM}$ human $\left[{ }^{125} \mathrm{I}\right] \mathrm{CGRP}, 10 \mathrm{pM}$ human $\left[{ }^{125} \mathrm{I}\right] \mathrm{AM}$, or $40 \mathrm{pM}$ rat $\left[{ }^{125} \mathrm{I}\right]$ AMY in the presence of several concentrations of ubrogepant. The assays were terminated by filtration through $0.5 \%$ polyethyleneiminetreated GF/B glass fiber filter plates with ice-cold wash buffer $(10 \mathrm{mM}$ HEPES, $\mathrm{pH} 7.4$ and $5 \mathrm{mM} \mathrm{MgCl} 2$ ). Scintillation fluid was added to the plates and radioactivity quantitated using a Packard TopCount NXT scintillation counter (PerkinElmer, Shelton, CT). Dose-response curves were plotted to determine half-maximal inhibitory concentration $\left(\mathrm{IC}_{50}\right)$ values and converted to $K_{\mathrm{i}}$ values using the equation $K_{\mathrm{i}}=\mathrm{IC}_{50} / \mathrm{l}+$ ([ligand] $) / K_{\mathrm{d}}$ ). Data are presented descriptively using group means and S.E.M.s, unless otherwise noted.

Functional Potency. The effect of ubrogepant on CGRP-, AM-, or CT-induced increases in cyclic adenosine monophosphate (cAMP) was assessed in HEK293 cells expressing human CGRP receptors, rhesus CGRP receptors, cloned human $\mathrm{AM}_{1}$ (CLR/RAMP2), $\mathrm{AM}_{2}$ (CLR/ RAMP3), cloned human $\mathrm{AMY}_{1}$ (CTR/RAMP1) or $\mathrm{AMY}_{3}$ (CTR/ RAMP3), or human CTR alone.

Cells were pre-incubated at 2000 cells/well in 384-well plates with various concentrations of ubrogepant for 30 minutes at $37^{\circ} \mathrm{C}$. In the human CGRP receptor functional assays, potency was assessed with and without $50 \%$ human or rhesus serum. The cyclic nucleotide inhibitor isobutyl-methylxanthine was added to the cells at a concentration of $300 \mu \mathrm{M}$ for 30 minutes at $37^{\circ} \mathrm{C}$ followed by stimulation with $1.0 \mathrm{nM}$ human $\alpha$-CGRP (human and rhesus CGRP receptor assays), $1.0 \mathrm{nM}$ human $\mathrm{AM}$ (human $\mathrm{AM}_{1}$ and $\mathrm{AM}_{2}$ receptor assays), $0.5 \mathrm{nM}$ rat $\mathrm{AMY}$ (cloned human $\mathrm{AMY}_{1}$ and $\mathrm{AMY}_{3}$ receptor assays), or $0.2 \mathrm{nM}$ human CT (human CTR assay) for 20 minutes at $37^{\circ} \mathrm{C}$. After agonist stimulation, cAMP concentration was measured with the homogeneous time-resolved fluorescence cAMP Dynamic Assay (Cisbio, Bedford, MA).

Dose-response curves were plotted and IC $_{50}$ values determined from a four-parameter logistic fit as defined by the equation $\mathrm{y}=[(\mathrm{a}-$ $\left.\mathrm{d}) /(1+\mathrm{x} / \mathrm{c})^{\mathrm{b}}\right]+\mathrm{d}$, where $\mathrm{y}=$ response, $\mathrm{x}=$ dose, $\mathrm{a}=$ maximum response, $d=$ minimum response, $c=$ inflection point, and $b=$ slope. For the CGRP assays, Schild analysis was used as a measure of competitive antagonism by plotting log (DR-1) versus log $[B]$, where $\mathrm{DR}$ is the ratio of $\alpha$-CGRP half-maximal effective concentration $\left(\mathrm{EC}_{50}\right.$ values in the presence and absence of ubrogepant and $[\mathrm{B}]$ is the antagonist concentration. The $\mathrm{X}$-intercept is equal to the $\mathrm{pA}_{2}$ and the $K_{\mathrm{B}}$ calculated using the formula $\mathrm{pA}_{2}=-\log K_{\mathrm{B}}$.

Specificity/Off-Target Profiling. The specificity of ubrogepant was assessed in ligand binding or functional assays across 116 targets (Supplemental Table 1; Olon Ricerca Bioscience, Concord, OH) and against the human ether-a-go-go-related gene (hERG), which encodes the inward-rectifying voltage-gated potassium channel in the heart and is involved in cardiac repolarization. Ubrogepant was tested at a concentration of $10 \mu \mathrm{M}$ in conventional radioligand binding and enzyme assays, and a concentration dose-response curve was generated when significant activity was observed.

The hERG ligand-binding assay was conducted using membrane fractions isolated from HEK293 cells stably expressing cloned hERG. $\left.{ }^{35} \mathrm{~S}\right]$ MK-499 (Wang et al., 2003) was used as the radioligand and $10 \mu \mathrm{M}$ astemizole (Suessbrich et al., 1996) was used to determine nonspecific binding. Binding assays were conducted in $1 \mathrm{ml}$ of binding buffer $\left(60 \mathrm{mM} \mathrm{KCl}, 71.5 \mathrm{mM} \mathrm{NaCl}, 1 \mathrm{mM} \mathrm{CaCl}_{2}, 2 \mathrm{mM} \mathrm{MgCl}_{2}\right.$, and $10 \mathrm{mM}$ HEPES, $\mathrm{pH}$ 7.4) containing $25 \mathrm{pM}\left[{ }^{35} \mathrm{~S}\right] \mathrm{hERG}$ ligand in the presence of several concentrations of ubrogepant for 3 hours at room temperature. The assay was terminated by filtration through $0.05 \%$ polyethyleneimine-treated GF/B glass fiber plates with ice-cold wash buffer (10 mM HEPES, $\mathrm{pH}$ 7.4). Plates were dried under vacuum at $37^{\circ} \mathrm{C}$ for 1 hour, scintillation fluid was added, and radioactivity quantitated using a Packard TopCount NXT scintillation counter. 
Binding Kinetics. Saturation binding assays were performed by combining increasing concentrations of $\left[{ }^{3} \mathrm{H}\right]$-ubrogepant, $10 \mu \mathrm{M}$ CGRP receptor antagonist MK-3207 for nonspecific binding, and $50 \mu \mathrm{g}$ SK-N-MC membranes per well. The mixtures were incubated overnight (18 hours) at room temperature in binding buffer $(10 \mathrm{mM}$ HEPES, $\mathrm{pH} 7.4,5 \mathrm{mM} \mathrm{MgCl}_{2}$, and $0.2 \%$ bovine serum albumin) in a total volume of $1 \mathrm{ml}$.

Association kinetic assays were performed by combining $40 \mathrm{pM}$ $\left[{ }^{3} \mathrm{H}\right]$-ubrogepant with $50 \mu \mathrm{g}$ SK-N-MC membranes per well in binding buffer and incubating at room temperature for various times (1-90 minutes). Dissociation kinetic assays were performed by combining $40 \mathrm{pM}\left[{ }^{3} \mathrm{H}\right]$-ubrogepant with $50 \mu \mathrm{g}$ SK-N-MC membranes per well in binding buffer and incubating at room temperature for 3 hours. At that point, $10 \mu \mathrm{M}$ of the CGRP receptor antagonist MK-3207 was added and dissociation was monitored for various intervals (1-300 minutes). All assays were terminated by filtration through $0.5 \%$ polyethyleneimine-treated GF/B glass fiber plates with ice-cold wash buffer (10 mM HEPES, pH 7.4, and $5 \mathrm{mM}$ $\mathrm{MgCl}_{2}$ ). Plates were dried under vacuum at $37^{\circ} \mathrm{C}$ for 1 hour, scintillation fluid was added, and radioactivity quantitated using a Packard TopCount NXT scintillation counter.

\section{In Vivo Pharmacology: Assessment of Pharmacodynamic Effect}

The pharmacodynamic (PD) activity of CGRP receptor antagonists in vivo has been established and validated using the capsaicin-induced dermal vasodilatation (CIDV) model in both rhesus monkeys (Salvatore et al., 2008, 2010) and human clinical trials (Li et al., 2015). Therefore, the in vivo PD activity of ubrogepant was assessed using CIDV assay in rhesus monkeys and humans in this study. The protocol for the human CIDV study was reviewed and approved by the Independent Ethics Committee of the University Hospitals of Leuven, Belgium. Before enrollment, all participants gave informed consent in writing after a full verbal and written explanation of the study. The study was conducted in accordance with local law, the ethical principles of the Declaration of Helsinki, and Good Clinical Practice guidelines.

Rhesus Monkey CIDV. Twenty-one adult rhesus monkeys ( $\leq 10$ per individual study) were used across six studies to determine the effect of vehicle and active test agent on CIDV. Animals were provided at least 5-7 procedure-free days between studies. For the CIDV test, animals were maintained on isoflurane anesthesia, and four O-rings ( $8 \mathrm{~mm}$ internal diameter) were placed on the ventral forearm. After equilibration, the baseline response 20 minutes after application of $2 \mathrm{mg}$ capsaicin (dissolved in 30\% ethanol, 30\% Tween20, and $40 \%$ water) in one ring was measured using a laser Doppler imager (Moor Instruments, Wilmington, DE).

Next, three successive intravenous bolus + intravenous infusions of vehicle or one to three rising doses of ubrogepant were administered. Five minutes after the start of each infusion, $2 \mathrm{mg}$ capsaicin was applied to one of the remaining rings. Scans were completed for each ring before the start of each infusion and 20 minutes after capsaicin application (i.e., 25 minutes after start of infusion). Study A targeted ubrogepant plasma levels of $0.5,5$, and $50 \mathrm{nM}$ in five male and two female rhesus monkeys; Study B targeted plasma levels of 5, 50, and $150 \mathrm{nM}$ in six male and one female rhesus monkeys; Study C targeted plasma levels of 1,5 , and $10 \mathrm{nM}$ in three female rhesus monkeys; Study D targeted plasma levels of 150,500, and $500 \mathrm{nM}$ in seven male rhesus monkeys; Study E targeted plasma levels of 1, 10, and $10 \mathrm{nM}$ in two male and two female rhesus monkeys; and Study F targeted plasma levels of $400 \mathrm{nM}$ in 10 male rhesus monkeys. Dosages were calibrated to achieve specified target plasma levels and to provide adequate coverage of the dynamic range of the pharmacokinetic (PK)/ PD curve.

Blood samples to determine plasma ubrogepant concentrations, response curves, and inhibitory concentrations were obtained at 20 minutes after application during each test period. An empirical maximal effect $\left(\mathrm{E}_{\max }\right)$ model was used to describe the PK/PD relationship of ubrogepant for inhibition of CIDV in rhesus monkeys. Blood flow was described as a baseline blood flow plus an incremental blood flow as a result of CIDV and blockade of CIDV by ubrogepant through an $\mathrm{E}_{\max }$ relationship. The model was represented as $\mathrm{F}=\mathrm{F}_{0}+$ $\mathrm{F}_{\text {caps }} \bullet\left[1-\mathrm{E}_{\max } \bullet \mathrm{C} /\left(\mathrm{EC}_{50}+\mathrm{C}\right)\right]$, where $\mathrm{F}$ is the observed blood flow (mean perfusion values) measured by laser Doppler imaging, $\mathrm{F}_{0}$ the baseline blood flow, $\mathrm{F}_{\text {caps }}$ the incremental blood flow due to application of capsaicin, $\mathrm{E}_{\max }$ the maximal percentage inhibition of ubrogepant, $\mathrm{C}$ the plasma concentration of ubrogepant, and $\mathrm{EC}_{50}$ the plasma concentration of ubrogepant corresponding to $50 \%$ inhibition of CIDV. Data were pooled across six rhesus CIDV studies (intravenous dose range from 0.06 to $100 \mu \mathrm{g} / \mathrm{kg}$ ) (see Supplemental Table 2 for doses for each study). Interindividual variability parameters were selected using forward substitution (significance level of 0.05) for $\mathrm{F}_{0}, \mathrm{~F}_{\text {caps }}$, $\mathrm{E}_{\max }$, and $\mathrm{EC}_{50}$. Covariate assessments focused on looking for studyto-study differences in $\mathrm{F}_{0}$ and response to capsaicin $\left(\mathrm{F}_{\text {caps }}\right)$. Model fitting was performed using NONMEM VII (ICON plc, Dublin, Ireland) using first-order conditional estimation with interaction.

Human CIDV. Healthy young males aged 18-50 years were administered oral ubrogepant during a randomized, double-blind, placebo-controlled, four-period crossover study (EudraCT Number: 2011-002359-32). Participants were required to fast for 8 hours before their ubrogepant dosing and pretreatment procedures. Inhibition of CIDV was measured by laser Doppler scan at 1 and 5 hours after a single oral dose of ubrogepant $(0.5 \mathrm{mg}, 5 \mathrm{mg}$, and $40 \mathrm{mg})$. The doses were selected to capture the expected dynamic range of exposureresponse curve based on the estimated $\mathrm{EC}_{50}$ of $3.2 \mathrm{nM}$ from rhesus CIDV experiments. Doppler scans were also conducted before the study (for inclusion purposes) and before study drug administration (predose). Capsaicin was applied 30 minutes before each postdose laser Doppler scan at 0.5 and 4.5 hours after study drug administration. Capsaicin was applied as single topical doses of $300 \mu \mathrm{g} / 20 \mu \mathrm{l}$ and $1000 \mu \mathrm{g} / 20 \mu \mathrm{l}$ capsaicin in 10-mm rubber O-rings at two sites on the volar surface of the participant's left and right forearms. The data were used to determine the concentration of drug necessary to achieve the $\mathrm{EC}_{90}$ using PK/PD modeling and using two doses of capsaicin, with an approach similar to the primate studies outlined above.

\section{Brain Penetration Studies}

CGRP Receptor Occupancy by Ubrogepant in Rhesus Monkey Brain by Positron Emission Tomography. All animal studies were conducted in accord with the Guide for the Care and Use of Laboratory Animals (Institute of Laboratory Animal Resources, Commission on Life Sciences, National Research Council, 2011) and were approved by the Institutional Animal Care and Use Committee at Merck \& Co., Inc. (West Point, PA). The quantification of CGRP receptor occupancy by ubrogepant was conducted in four anesthetized adult male rhesus monkeys by positron emission tomography (PET), using the PET tracer for the CGRP receptor $\left[{ }^{11} \mathrm{C}\right]$ MK-4232 (Hostetler et al., 2013). A baseline PET scan was performed with $\left[{ }^{11} \mathrm{C}\right] \mathrm{MK}-4232$ in the absence of ubrogepant. To establish steady plasma levels of study drug, an intravenous bolus plus constant infusion of ubrogepant

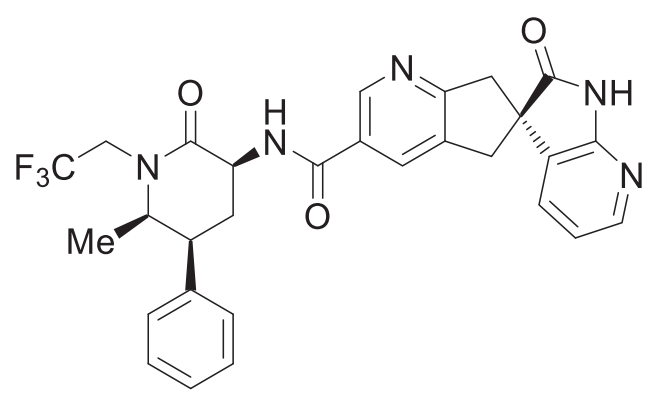

Fig. 1. Chemical structure of ubrogepant. 
TABLE 1

Mean (S.E.M.) binding affinities $\left(K_{\mathrm{i}}, \mathrm{nM}\right)$ of ubrogepant for human and nonhuman CGRP receptors ${ }^{a}$

\begin{tabular}{lccccccc}
\hline Species & Human Cloned & Human SK-N-MC & Rhesus & Rat & Mouse & Rabbit & Dog \\
\hline Binding affinity & $0.07 \pm 0.006$ & $0.067 \pm 0.004$ & $0.079 \pm 0.005$ & $9.6 \pm 1.1$ & $11.6 \pm 1.1$ & $11.0 \pm 0.5$ & $47.0 \pm 4.0$ \\
\hline
\end{tabular}

SK-N-MC, human neuroblastoma cell line.

${ }^{a} n=3-19$.

was started 60 minutes before intravenous bolus injection of $\sim 5 \mathrm{mCi}$ $\left[{ }^{11} \mathrm{C}\right] \mathrm{MK}-4232$ and continuing for the duration of the scan. PET studies were acquired for 120 minutes after $\left[{ }^{11} \mathrm{C}\right] \mathrm{MK}-4232$ administration.

Plasma concentrations of $\left[{ }^{11} \mathrm{C}\right] \mathrm{MK}-4232$ for each study were obtained from the measurement of total radioactivity in arterial plasma, with correction for the fraction of intact tracer as determined by high-performance liquid chromatography, and plasma levels of ubrogepant were determined from arterial blood samples. Tissue time-activity curves were fit, and receptor occupancy was calculated using the Lassen plot. For each receptor-occupancy PET study, the estimated receptor occupancy was associated with the average plasma drug levels during the PET scan.

Cerebrospinal Fluid Penetration of Ubrogepant in Rhesus Monkeys. The cerebrospinal fluid (CSF):plasma ratio of ubrogepant was assessed in three adult male rhesus monkeys with chronically implanted cisterna magna catheters and port systems for repeated noninvasive collection of CSF. Additional details related to CSF collection have been previously published (Gilberto et al., 2003; Salvatore et al., 2010). After oral gavage of ubrogepant at $10 \mathrm{mg} / \mathrm{kg}$, CSF and plasma samples were collected at baseline and 0.5, 1, 2, 4, 8, and 24 hours and analyzed for compound levels.

\section{Results}

Ubrogepant is an orally bioavailable CGRP receptor antagonist developed for the acute treatment of migraine. The chemical structure of ubrogepant is presented in Fig. 1.

Receptor Binding and Functional Potency of Ubrogepant. Ubrogepant was a potent inhibitor of $\left[{ }^{125} \mathrm{I}\right] \mathrm{CGRP}$ binding to the cloned and native human CGRP receptors with a mean $K_{\mathrm{i}}( \pm$ S.E.M.) of $0.07 \pm 0.006 \mathrm{nM}$ and $0.067 \pm 0.004 \mathrm{nM}$, respectively (Table 1). Comparable affinity for ubrogepant was observed with the rhesus CGRP receptor $0.079 \pm 0.005 \mathrm{nM}$; however, markedly lower affinity was found for rat, mouse, rabbit, and dog receptors $\left(K_{\mathrm{i}}>9.5 \mathrm{nM}\right)$. Affinity for the human $\mathrm{AM}_{2}$ receptor was significantly lower $\left(K_{\mathrm{i}}=2059 \pm 122 \mathrm{nM}\right)$ than that for the human CGRP receptor, but ubrogepant did display moderate affinity for the recombinant human $\mathrm{AMY}_{1}$ receptor by inhibiting $\left[{ }^{125} \mathrm{I}\right]-\mathrm{rAMY}$ binding with a $K_{\mathrm{i}}$ of $8.2 \mathrm{nM}$ (individual $K_{\mathrm{i}}=6.5,9.8$ ).

Ubrogepant potently blocked human $\alpha$-CGRP-stimulated cAMP responses with a mean $( \pm$ S.E.M. $) \mathrm{IC}_{50}$ of $0.081 \mathrm{nM}$ $(0.005 \mathrm{nM})$ in human CGRP receptor-expressing HEK293 cells and $0.07 \mathrm{nM}(0.02 \mathrm{nM})$ in rhesus CGRP receptor-expressing HEK293 cells (Table 2). The addition of 50\% human or $50 \%$ rhesus serum reduced the apparent potency of ubrogepant by approximately 2.4 - and 4.0 -fold for human $(0.19 \pm 0.01$ $\mathrm{nM})$ and rhesus $(0.30 \pm 0.01 \mathrm{nM})$ CGRP receptors, respectively. Using Schild regression, ubrogepant caused potent, dose-dependent rightward shifts (data not shown) in the agonist dose-response curves, $K_{\mathrm{B}}=0.017 \mathrm{nM}$, with no reduction in the maximal agonist response.

Specificity and Selectivity of Ubrogepant. In a specificity assessment against 116 enzyme, receptor, and ion channel binding assays (Supplemental Table 1), ubrogepant showed weak affinity for the dopamine transporter $\left(K_{\mathrm{i}}=4440\right.$ $\mathrm{nM}$ ), which is significantly lower than its affinity for the CGRP receptor. Saturation binding studies using $\left[{ }^{3} \mathrm{H}\right]$-ubrogepant demonstrated that specific binding was saturable to SK-N-MC membranes, with a $\mathrm{K}_{\mathrm{D}}$ of $0.041 \mathrm{nM}$.

Ubrogepant displayed no significant antagonism of AMinduced cAMP stimulation of the human $\mathrm{AM}_{1}$ or the human CTR at concentrations greater than $20,000 \mathrm{nM}$, whereas potency was somewhat greater at the $\mathrm{AM}_{2}$ receptor and consistent with binding data for that receptor (Table 3). Similarly, in blockade of AMY-stimulated cAMP responses, ubrogepant demonstrated antagonist activity on the human $\mathrm{AMY}_{1}$ and $\mathrm{AMY}_{3}$ receptors at potencies comparable to its affinity for those receptors based on $\left.{ }^{125} \mathrm{I}\right]$-rAMY binding (Table 3 ).

Pharmacodynamic Assessment. Dermal vasodilation response to capsaicin was found to be concentration- and time-dependent. Application of vehicle alone did not significantly inhibit resulting blood flow increases. The PK/PD relationship for inhibition of CIDV by ubrogepant was estimated based on data from six rhesus CIDV studies (Study A-F, with intravenous doses ranging from 0.06 to $100 \mu \mathrm{g} / \mathrm{kg}$ ) using a population $\mathrm{E}_{\max }$ model (Supplemental Table 2). Studies $\mathrm{E}$ $(0.3$ and $3 \mu \mathrm{g} / \mathrm{kg})$ and $\mathrm{F}(50 \mu \mathrm{g} / \mathrm{kg})$ were found to be significant covariates for baseline blood flow before administration of capsaicin or ubrogepant (i.e., $\mathrm{F}_{0}$ ) (Fig. 2). Ubrogepant has a mean $\mathrm{EC}_{50}$ of $3.19 \mathrm{nM}$ (S.E.M., $3.65 \mathrm{nM}$; Supplemental Table 3), corresponding to an estimated $\mathrm{EC}_{90}$ of $29 \mathrm{nM}$. The $\mathrm{E}_{\max }$ for inhibition of CIDV by ubrogepant is $0.732( \pm 0.0859)$.

In the human PD study of CIDV, a dose-dependent decrease was observed with a single dose of ubrogepant compared with placebo at 1 and 5 hours postdose, regardless of capsaicin concentration used (Table 4). The estimated $\mathrm{EC}_{50}$ and $\mathrm{EC}_{90}$ values for ubrogepant for inhibition of CIDV in humans were 2.56 and $23 \mathrm{nM}$, respectively.

Brain Penetration. In assessments of CGRP receptor occupancy in adult male rhesus monkey brain by PET, ubrogepant achieved receptor occupancy $(0 \%-16 \%)$ at plasma levels of 53-203 $\mathrm{nM}$, which are higher than the rhesus monkey CIDV EC $\mathrm{EC}_{90}$ of $29 \mathrm{nM}$. Tests of central nervous system (CNS) penetration of ubrogepant in cisterna magna-ported conscious adult male rhesus monkeys found a CSF-to-plasma concentration ratio of 0.03 (Table 5).

\section{TABLE 2}

Mean (S.E.M.) functional potency $\left(\mathrm{IC}_{50}, \mathrm{nM}\right)$ of ubrogepant for cloned CGRP receptors in HEK293 cells ${ }^{a}$

\begin{tabular}{lccc}
\hline \multicolumn{2}{l}{ Cloned Human CGRP Receptor } & \multicolumn{2}{c}{ Cloned Rhesus CGRP Receptor } \\
\hline No Serum & $+50 \%$ Human & No Serum & $+50 \%$ Rhesus \\
& Serum & & Serum \\
$0.081 \pm 0.005$ & $0.19 \pm 0.01$ & $0.07 \pm 0.02$ & $0.30 \pm 0.01$ \\
\hline
\end{tabular}

$\mathrm{IC}_{50}$, half-maximal inhibitory concentration.
$a_{n}=3-21$. 
TABLE 3

Selectivity of ubrogepant for cloned CTR, $\mathrm{AM}_{1}, \mathrm{AM}_{2}, \mathrm{AMY}_{1}$, and $\mathrm{AMY}_{3}$ receptors in HEK293 cells $^{a}$

\begin{tabular}{lc}
\hline Target Receptor & $\begin{array}{c}\text { Selectivity } \\
\text { Potency Difference Over CGRP Receptor } \\
\left(\mathrm{IC}_{50}=0.08 \mathrm{nM}\right)\end{array}$ \\
\hline $\mathrm{AM}_{1}$ & $>10,000$ \\
$\mathrm{AM}_{2}$ & $>10,000$ \\
$\mathrm{Calcitonin}^{b}$ CTR) & $>10,000$ \\
$\mathrm{AMY}_{1}$ & 105 \\
$\mathrm{AMY}_{3}$ & 2737 \\
\hline
\end{tabular}

$\mathrm{IC}_{50}$, half-maximal inhibitory concentration.

${ }^{a} n=3-19$.

${ }^{b}$ Calculated as (target receptor $\mathrm{IC}_{50}-\mathrm{CGRP}$ receptor $\mathrm{IC}_{50}$ )/CGRP receptor $\mathrm{IC}_{50}$.

\section{Discussion}

Ubrogepant is a potent CGRP receptor antagonist developed for use in the acute treatment of migraine. In the present study, ubrogepant exhibited a high affinity for the human CGRP receptor $\left(K_{\mathrm{i}}, 0.07 \mathrm{nM}\right)$. Additionally, ubrogepant exhibited species specificity, showing high affinity for the human and rhesus CGRP receptor and reduced affinity for other nonhuman receptors.

Ubrogepant displayed high selectivity for the human CGRP receptor versus the human $\mathrm{AM}_{1}, \mathrm{AM}_{2}, \mathrm{CT}$, and $\mathrm{AMY}_{3}$ receptors but selectivity was reduced against the $\mathrm{AMY}_{1}$ receptor. This observation is consistent with the RAMP1-dependence of other small-molecule CGRP receptor antagonists (Moore and Salvatore, 2012; Walker et al., 2015). Incubation of HEK293 cells expressing the human CGRP receptor with ubrogepant blocked the $\alpha$-CGRP-stimulated cAMP response, with an $\mathrm{IC}_{50}$ of $0.08 \mathrm{nM}$. Increasing concentrations of ubrogepant caused parallel rightward shifts in the $\alpha$-CGRP dose-response curves in the cAMP functional assay, and the dose-ratio plot displayed a straight line. Additionally, screenings of 116 off targets showed that ubrogepant was highly selective for the CGRP receptor, with weak binding affinity for dopamine transporter $\left(K_{\mathrm{i}}\right.$ of $\left.4440 \mathrm{nM}\right)$. This dopamine activity is likely to be pharmacologically irrelevant at the plasma concentrations projected shown to be efficacious doses in humans.

In the CIDV model in the rhesus monkey, capsaicin activates vanilloid receptor 1 , producing neurogenic inflammation and vasodilation via activation of dorsal root reflexes and the release of vasoactive mediators, which is driven primarily by CGRP. This response can be blocked by CGRP receptor antagonists, thus permitting the assessment of ubrogepant potency in vivo against endogenously released CGRP (Dux et al., 2003; Hershey et al., 2005). Based on the $\mathrm{PK} / \mathrm{PD}$ relationship for inhibition of CIDV by ubrogepant, the estimated mean $\mathrm{EC}_{50}$ and $\mathrm{EC}_{90}$ values were 3.19 and $29 \mathrm{nM}$, respectively. Population PK/PD CIDV modeling in the present rhesus in vivo study showed that the $\mathrm{E}_{\max }$ for inhibition of CIDV by ubrogepant is 0.732 , suggesting that CGRP is the primary, but not the only, contributor to CIDV (substance-P and histamine may also play a role in vasodilation), which is generally consistent with results from other CIDV studies for CGRP compounds (Vu et al., 2017). Similar results were observed in human studies using the CIDV model and resulted in similar estimates for mean $\mathrm{EC}_{50}$ and $\mathrm{EC}_{90}$ values of 2.56 and $23 \mathrm{nM}$, respectively. Taken together, these rapid assessments of CGRP receptor antagonism activity in nonhuman primates and human participants indicate a predictable PK-PD relationship for ubrogepant across species.

In the CNS penetration study, the CSF:plasma ratio was 0.03 . Limited penetration into the CNS suggests that ubrogepant does not readily cross the blood-brain barrier, which was supported by the present receptor occupancy data that showed low central CGRP receptor occupancy (0\%-16\%) at plasma levels of 53-203 nM. Although the exact site of action of CGRP receptor antagonists is not known, the limited penetration of ubrogepant

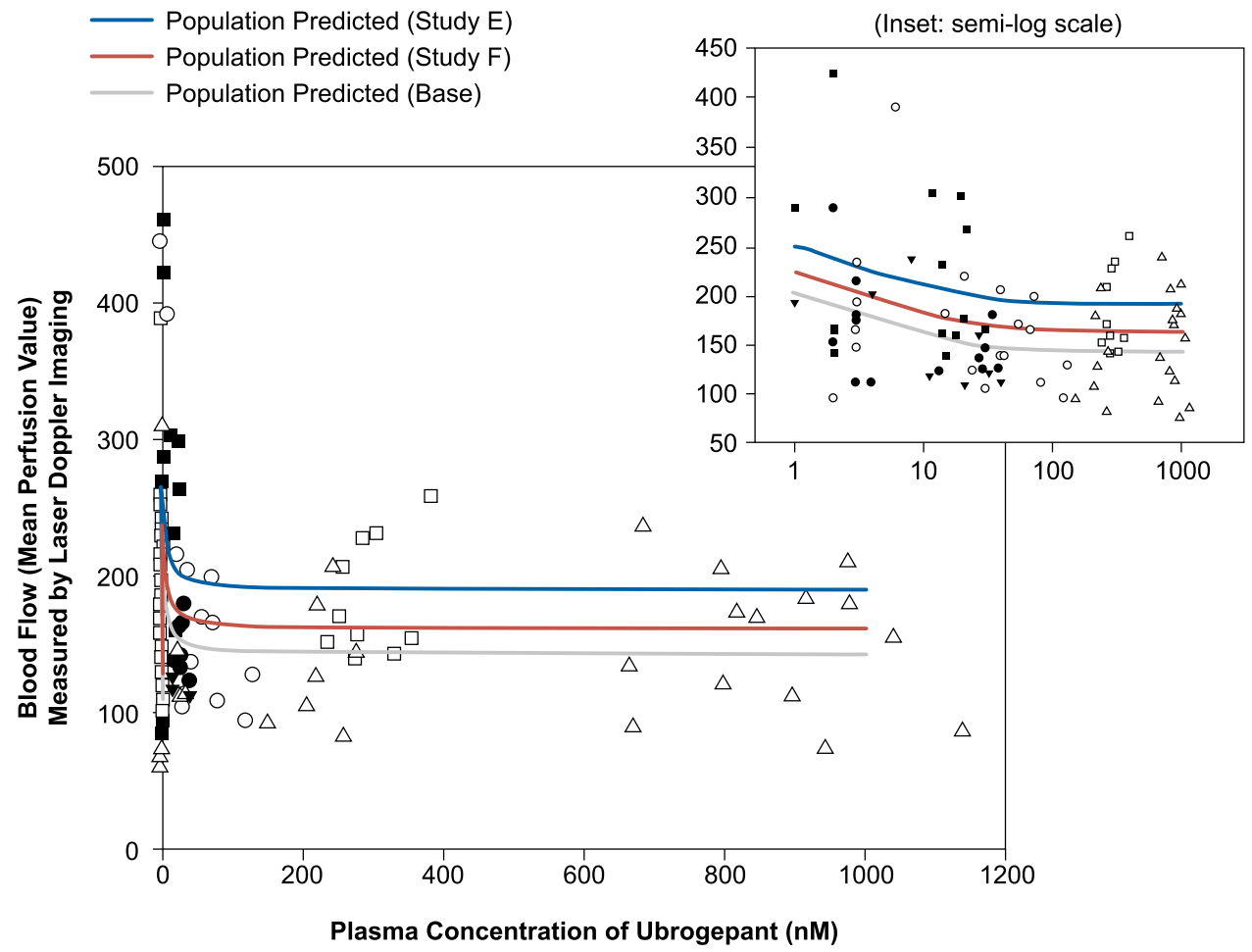

Fig. 2. Ubrogepant dose-dependent inhibition of capsaicin-induced dermal vasodilation in the rhesus forearm: population model-predicted vs. observed blood flow after $2 \mathrm{mg}$ capsaicin application at different plasma concentrations of ubrogepant. Data pooled from six rhesus CIDV studies (Studies A to $\mathrm{F}$ with intravenous dose range from 0.06 to $100 \mu \mathrm{g} / \mathrm{kg}$ ) represented by symbols. Solid lines represent modelpredicted population mean values. Studies $\mathrm{E}$ and $\mathrm{F}$ were found to have statistically significant differences in the baseline blood flow (i.e., before administration of capsaicin or ubrogepant) and thus the model-predicted population means are shown separately. 
TABLE 4

Summary of capsaicin-induced dermal blood flow (mean perfusion) after single oral administration of ubrogepant or placebo with capsaicin 300 or $1000 \mu \mathrm{g} / 20 \mu \mathrm{l}$

Root mean square error on $\log$ scale from model: 0.384 at $1 \mathrm{~h}$ and $300 \mathrm{mg} / 20 \mathrm{ml}, 0.290$ at $5 \mathrm{~h}$ and $300 \mathrm{mg} / 20 \mathrm{ml}, 0.345$ at $1 \mathrm{~h}$ and $1000 \mathrm{mg} / 20 \mathrm{ml}, 0.284$ at $5 \mathrm{~h}$ and $1000 \mathrm{mg} / 20 \mathrm{ml}$.

\begin{tabular}{|c|c|c|c|c|}
\hline \multirow{2}{*}{$\begin{array}{l}\text { Capsaicin Conc. }^{b} \\
(\mu \mathrm{g} / 20 \mu \mathrm{l})\end{array}$} & \multirow{2}{*}{ Treatment } & \multirow{2}{*}{$N$} & \multicolumn{2}{|c|}{ Percentage Inhibition (90\% CI) ${ }^{a}$} \\
\hline & & & $1 \mathrm{~h}$ & $5 \mathrm{~h}$ \\
\hline \multirow{4}{*}{300} & Placebo & 16 & & \\
\hline & $0.5 \mathrm{mg}$ & 16 & $22.6(2.7,38.4)$ & $15.5(-0.8,29.1)$ \\
\hline & $5 \mathrm{mg}$ & 14 & $53.4(40.8,63.3)$ & $65.2(58.3,70.9)$ \\
\hline & $40 \mathrm{mg}$ & 16 & $63.4(54.0,70.9)$ & $65.1(58.4,70.8)$ \\
\hline \multirow[t]{4}{*}{1000} & Placebo & 16 & & \\
\hline & $0.5 \mathrm{mg}$ & 16 & $27.1(9.5,41.3)$ & $3.1(-14.7,18.2)$ \\
\hline & $5 \mathrm{mg}$ & 14 & $60.8(50.7,68.7)$ & $60.7(53.3,67.0)$ \\
\hline & $40 \mathrm{mg}$ & 16 & $64.9(56.5,71.7)$ & $63.9(57.3,69.5)$ \\
\hline
\end{tabular}

${ }^{a}$ Percentage inhibition of dermal blood flow calculated as $(1-$ GMR $) \times 100$ percent. Root mean square error on log scale from model: 0.384 at $1 \mathrm{~h}$ and $300 \mu \mathrm{g} / 20 \mu \mathrm{l}, 0.290$ at $5 \mathrm{~h}$ and $300 \mu \mathrm{g} / 20 \mu \mathrm{l}, 0.345$ at $1 \mathrm{~h}$ and $1000 \mu \mathrm{g} / 20 \mu \mathrm{l}, 0.284$ at $5 \mathrm{~h}$ and $1000 \mu \mathrm{g} / 20 \mu \mathrm{l}$

${ }^{b}$ Capsaicin was applied 0.5 and $4.5 \mathrm{~h}$ after administration of ubrogepant.

to the CNS is consistent with the concept that during a neurovascular headache, sensitization and activation of the trigeminovascular system results in perivascular release of neuropeptides such as CGRP (Goadsby et al., 1988; Ho et al., 2010). The trigeminal ganglion is located outside of the bloodbrain barrier and thus can be readily impacted by CGRPfocused treatments (Eftekhari et al., 2015). The limited CNS activity of ubrogepant may be beneficial in avoiding potential side effects of central CGRP antagonism, and the potential clinical benefit of this limited CNS activity is unknown.

In addition to high affinity for the CGRP receptor, ubrogepant displays affinity for the $\mathrm{AMY}_{1}$ receptor and, to a lesser degree, the $\mathrm{AMY}_{3}$ receptor. The 100-fold difference in ubrogepant potency between the CGRP receptor and $\mathrm{AMY}_{1}$ receptor could be representative of the difference in $\alpha$-CGRP binding between the two receptors, suggesting that ubrogepant may have a binding site similar to that of CGRP. The identification of CGRP-responsive $\mathrm{AMY}_{1}$ receptors in the trigeminal ganglia neurons and the expression of CTR and RAMP1 proteins in the spinal trigeminal complex suggests a role for these receptors in the central processing of CGRP signaling (Walker et al., 2015). Furthermore, animal knockout studies have identified a pro-nociceptive role for $\mathrm{AMY}_{1}$ (Gebre-Medhin et al., 1998). However, the role of the $\mathrm{AMY}_{1}$ receptor in migraine remains largely unknown.

Inhibition of the CGRP receptor has emerged as a promising target for the acute and preventive treatment of migraine (Edvinsson, 2018). Previously investigated small-molecule CGRP antagonists have demonstrated efficacy in the treatment of migraine; however, clinical studies involving telcagepant and MK-3207 revealed potential concerns regarding drug-induced elevation of liver enzymes, and clinical development of these compounds was discontinued (Hewitt et al., 2011; Ho et al., 2014; Hargreaves and Olesen, 2019). Although the exact mechanism of this hepatotoxicity is unknown, it was hypothesized to be partly attributable to the formation of reactive metabolites and not specific to CGRP receptor antagonism (Hargreaves and Olesen, 2019). The absence of any ubrogepant-associated hepatotoxicity has been supported by safety data from recent clinical studies (Goadsby et al., 2019; Hutchinson et al., 2019).

Monoclonal antibodies to CGRP and the CGRP receptor have demonstrated efficacy in people with migraine; however, these
TABLE 5

In vivo central nervous system penetration properties of ubrogepant

\begin{tabular}{lcc}
\hline & \multicolumn{2}{c}{$10 \mathrm{mg} / \mathrm{kg}$} \\
\cline { 2 - 3 } & $\mathrm{C}_{\max }(\mathrm{nM})$ & $\mathrm{t}_{\text {max }}(\mathrm{h})$ \\
\hline CSF & $40.9 \pm 21.2$ & 4 \\
Plasma & $1345.4 \pm 537.8$ & 4 \\
CSF/plasma ratio & 0.03 & - \\
\hline
\end{tabular}

$\mathrm{C}_{\max }$, maximum plasma drug concentration; $t_{\max }$, time to $\mathrm{C}_{\max }$

medications are injectable medications approved for the preventive treatment of migraine (Tepper et al., 2017; Ajovy [package insert] 2018; Aimovig [package insert] 2018; Emgality [package insert] 2018; 2018a,b,c; Dodick et al., 2018; Stauffer et al., 2018). Efficacy for preventive treatment is generally measured at 1-month intervals and thus treatment options for migraine attacks are still needed for rapid relief (Tepper et al., 2017; Ajovy [package insert] 2018; Aimovig [package insert] 2018; Emgality [package insert] 2018; 2018a,b,c; Dodick et al., 2018b; Stauffer et al., 2018). Ubrogepant is an oral CGRP receptor antagonist approved for the acute treatment of migraine that is capable of providing freedom from pain at 2 hours (Dodick et al., 2018a; Lipton et al., 2018; Voss et al., 2016). Acute treatments are a mainstay of migraine attack management and may complement preventive treatments in some patients based on factors such as headache frequency, acute treatment response, and migraine-related disability (Goadsby and Sprenger, 2010). Furthermore, the oral route of administration for ubrogepant may be preferred by patients who require multiple acute treatments for migraine attacks, compared with the injection or infusion route of administration that is offered for sumatriptan and dihydroergotamine (O'Quinn et al., 1999, D.H.E. 45 [package insert] 2002.). Ubrogepant thus represents a new class of medication for the acute treatment of migraine attacks.

In conclusion, ubrogepant is a potent, selective, orally delivered, small-molecule competitive inhibitor of the human CGRP receptor that shows a predictable PK-PD relationship and limited penetration across the blood-brain barrier at clinically effective exposures.

\section{Acknowledgments}

The authors would like to acknowledge Jan N. de Huon, Marleen Dupré (both from Center for Clinical Pharmacology, University Hospitals Leuven and the Department of Pharmaceutical and Pharmacological Sciences, KU Leuven, Belgium), Tom Reynders (MSD Europe, Inc., Brussels, Belgium), and Eugene Marcantonio (Merck \& Co., Inc. Kenilworth, NJ) for the human capsaicin-induced dermal vasodilation assay model design and conduct, and John Plaza (Merck $\&$ Co., Inc., Kenilworth, NJ) for the human capsaicin-induced dermal vasodilation assay data analysis. Writing and editorial assistance were provided to the authors by Peloton Advantage, LLC, Parsippany, $\mathrm{NJ}$, and was funded by Allergan plc. The opinions expressed in this article are those of the authors. The authors received no honorarium/ fee or other form of financial support related to the development of this article. The authors would like to acknowledge Mona Purcell for conducting the monkey PET studies, Mangey Williams for analytical support, Aniket Joshi for PET data analysis, and Abhijeet Jayate for assistance writing the manuscript.

\section{Authorship Contributions}

Participated in research design: Moore, Bell, Burgey, Li, Hostetler, Salvatore.

Conducted experiments: Moore, Fraley, White, Regan, Danziger, Michener. 
Contributed new reagents or analytic tools: Hostetler.

Performed data analysis: Li.

Wrote or contributed to the writing of the manuscript: Moore, Fraley, Bell, Burgey, White, Li, Regan, Danziger, Michener, Hostetler, Banerjee, Salvatore.

\section{References}

Aimovig. Package insert. Amgen Inc., and Novartis Pharmaceuticals Corporation, Thousand Oaks, CA, and East Hanover, NJ.

Ajovy. Package insert. Teva Pharmaceuticals USA, Inc., North Wales, PA.

Burch R, Rizzoli P, and Loder E (2018) The prevalence and impact of migraine and severe headache in the United States: figures and trends from government health studies. Headache 58:496-505.

Dodick DW (2019) CGRP ligand and receptor monoclonal antibodies for migraine prevention: evidence review and clinical implications [published correction appears in Cephalalgia (2019) 39:1069]. Cephalalgia 39:445-458.

Dodick DW, Silberstein SD, Bigal ME, Yeung PP, Goadsby PJ, Blankenbiller T, Grozinski-Wolff M, Yang R, Ma Y, and Aycardi E (2018b) Effect of fremanezumab compared with placebo for prevention of episodic migraine: a randomized clinical trial. JAMA 319:1999-2008.

Dux M, Sántha P, and Jancsó G (2003) Capsaicin-sensitive neurogenic sensory vasodilatation in the dura mater of the rat. $J$ Physiol 552:859-867.

Edvinsson L (2015) The journey to establish CGRP as a migraine target: a retrospective view. Headache 55:1249-1255.

Edvinsson L (2018) The CGRP pathway in migraine as a viable target for therapies. Headache 58 (Suppl 1):33-47.

Edvinsson L and Warfvinge K (2019) Recognizing the role of CGRP and CGRP receptors in migraine and its treatment. Cephalalgia 39:366-373.

Eftekhari S and Edvinsson L (2010) Possible sites of action of the new calcitonin gene-related peptide receptor antagonists. Ther Adv Neurol Disorder 3:369-378.

Eftekhari S, Salvatore CA, Johansson S, Chen TB, Zeng Z, and Edvinsson L (2015) Localization of CGRP, CGRP receptor, PACAP and glutamate in trigeminal ganglion. Relation to the blood-brain barrier. Brain Res 1600:93-109.

Gebre-Medhin S, Mulder H, Zhang Y, Sundler F, and Betsholtz C (1998) Reduced nociceptive behavior in islet amyloid polypeptide (amylin) knockout mice. Brain Res Mol Brain Res 63:180-183.

Gilberto DB, Zeoli AH, Szczerba PJ, Gehret JR, Holahan MA, Sitko GR, Johnson CA, Cook JJ, and Motzel SL (2003) An alternative method of chronic cerebrospinal fluid collection via the cisterna magna in conscious rhesus monkeys. Contemp Top Lab Anim Sci 42:53-59.

Goadsby PJ, Edvinsson L, and Ekman R (1988) Release of vasoactive peptides in the extracerebral circulation of humans and the cat during activation of the trigeminovascular system. Ann Neurol 23:193-196.

Goadsby PJ, Edvinsson L, and Ekman R (1990) Vasoactive peptide release in the extracerebral circulation of humans during migraine headache. Ann Neurol 28: 183-187.

Goadsby PJ and Sprenger T (2010) Current practice and future directions in the prevention and acute management of migraine. Lancet Neurol 9.285-298.

Goadsby PJ, Tepper SJ, Watkins PB, Ayele G, Miceli R, Butler M, Severt L, Finnegan M, Szegedi A, Trugman JM, et al. (2019) Safety and tolerability of ubrogepan following intermittent, high-frequency dosing: randomized, placebo-controlled trial in healthy adults. Cephalalgia 39:1753-1761.

González-Hernández A, Marichal-Cancino BA, MaassenVanDenBrink A, and Villalón CM (2018) Side effects associated with current and prospective antimigraine pharmacotherapies. Expert Opin Drug Metab Toxicol 14:25-41.

Hargreaves R and Olesen $J$ (2019) Calcitonin gene-related peptide modulators - the history and renaissance of a new migraine drug class. Headache 59:951-970.

Hershey JC, Corcoran HA, Baskin EP, Salvatore CA, Mosser S, Williams TM, Koblan KS, Hargreaves RJ, and Kane SA (2005) Investigation of the species selectivity of a nonpeptide CGRP receptor antagonist using a novel pharmacodynamic assay. Regul Pept 127:71-77.

Hewitt DJ, Aurora SK, Dodick DW, Goadsby PJ, Ge YJ, Bachman R, Taraborelli D, Fan X, Assaid C, Lines C, et al. (2011) Randomized controlled trial of the CGRP receptor antagonist MK-3207 in the acute treatment of migraine. Cephalalgia 31:712-722.

Ho TW, Connor KM, Zhang Y, Pearlman E, Koppenhaver J, Fan X, Lines C, Edvinsson L, Goadsby PJ, and Michelson D (2014) Randomized controlled trial of the CGRP receptor antagonist telcagepant for migraine prevention. Neurology $\mathbf{8 3}$ : 958-966.

Ho TW, Edvinsson L, and Goadsby PJ (2010) CGRP and its receptors provide new insights into migraine pathophysiology. Nat Rev Neurol 6:573-582.

Holland S, Fanning KM, Serrano D, Buse DC, Reed ML, and Lipton RB (2013) Rates and reasons for discontinuation of triptans and opioids in episodic migraine: results from the American Migraine Prevalence and Prevention (AMPP) study. J Neurol Sci 326:10-17.

Hostetler ED, Joshi AD, Sanabria-Bohórquez S, Fan H, Zeng Z, Purcell M, Gantert L Riffel K, Williams M, O'Malley S, et al. (2013) In vivo quantification of calcitonin gene-related peptide receptor occupancy by telcagepant in rhesus monkey and human brain using the positron emission tomography tracer $\left[{ }^{11} \mathrm{C}\right] \mathrm{MK}-4232$ $J$ Pharmacol Exp Ther $\mathbf{3 4 7}$.

Humphrey PP (2007) The discovery of a new drug class for the acute treatment of migraine. Headache 47 (Suppl 1):S10-S19.

Hutchinson S, Dodick DW, Treppendahl C, Bennett NL, Yu S, Guo H, and Trugman JM (2019) Ubrogepant for the acute treatment of migraine: pooled safety and tolerability from ACHIEVE I and ACHIEVE II phase 3 studies. Headache 59 (Suppl 1):120.

Kiriyama Y and Nochi H (2018) Role and cytotoxicity of amylin and protection of pancreatic islet $\beta$-cells from amylin cytotoxicity. Cells 7.

Lassen LH, Haderslev PA, Jacobsen VB, Iversen HK, Sperling B, and Olesen J (2002) CGRP may play a causative role in migraine. Cephalalgia 22:54-61.
Li CC, Vermeersch S, Denney WS, Kennedy WP, Palcza J, Gipson A, Han TH Blanchard R, De Lepeleire I, Depré M, et al. (2015) Characterizing the PK/PD relationship for inhibition of capsaicin-induced dermal vasodilatation by MK-3207, an oral calcitonin gene related peptide receptor antagonist. Br J Clin Pharmacol 79:831-837.

Lipton RB, Buse DC, Serrano D, Holland S, and Reed ML (2013) Examination of unmet treatment needs among persons with episodic migraine: results of the American Migraine Prevalence and Prevention (AMPP) Study. Headache 53:1300-1311.

Lipton RB, Dodick DW, Ailani J, Lu K, Lakkis H, Finnegan M, Szegedi A, and Trugman JM (2018) Efficacy, safety, and tolerability of ubrogepant for the acute treatment of migraine: results from a single attack phase III study, $\mathrm{ACH}$ IEVE II. Headache 58:1315-1316.

Lipton RB, Dodick DW, Ailani J, Lu K, Finnegan M, Szegedi A, and Trugman JM (2019) Effect of Ubrogepant vs Placebo on Pain and the Most Bothersome Associated Symptom in the Acute Treatment of Migraine: The ACHIEVE II Randomized Clinical Trial. JAMA 322 (19), doi: 10.1001/jama.2019.16711 31742631

Martelletti P (2017) Acute treatment of migraine: quo vadis? Expert Opin Phar macother 18:1035-1037.

May A and Schulte LH (2016) Chronic migraine: risk factors, mechanisms and treatment. Nat Rev Neurol 12:455-464.

Messali AJ, Yang M, Gillard P, Tsai K, Tepper SJ, Bloudek LM, and Kori SH (2014) Treatment persistence and switching in triptan users: a systematic literature review. Headache 54:1120-1130.

Moore EL and Salvatore CA (2012) Targeting a family B GPCR/RAMP receptor complex: CGRP receptor antagonists and migraine. Br J Pharmacol 166:66-78.

O'Quinn S, Davis RL, Gutterman DL, Pait GD, and Fox AW (1999) Prospective largescale study of the tolerability of subcutaneous sumatriptan injection for acute treatment of migraine. Cephalalgia 19:223-231; discussion 200.

Petersen KA, Birk S, Kitamura K, and Olesen J (2009) Effect of adrenomedullin on the cerebral circulation: relevance to primary headache disorders. Cephalalgia 29:23-30. Poyner DR, Sexton PM, Marshall I, Smith DM, Quirion R, Born W, Muff R, Fischer JA, and Foord SM (2002) International Union of Pharmacology. XXXII. The mammalian calcitonin gene-related peptides, adrenomedullin, amylin, and calcitonin receptors. Pharmacol Rev 54:233-246.

Russell FA, King R, Smillie SJ, Kodji X, and Brain SD (2014) Calcitonin gene-related peptide: physiology and pathophysiology. Physiol Rev 94:1099-1142.

Salvatore CA, Hershey JC, Corcoran HA, Fay JF, Johnston VK, Moore EL, Mosser SD, Burgey CS, Paone DV, Shaw AW, et al. (2008) Pharmacological characterization of MK-0974 [N-[(3R,6S)-6-(2,3-difluorophenyl)-2-oxo-1-(2,2,2-trifluoroethyl) azepan-3-yl]-4-(2-oxo-2,3-dihydro-1H-imidazo[4,5-b]pyridin-1-yl)piperidine-1-carboxamide], a potent and orally active calcitonin gene-related peptide receptor antagonist for the treatment of migraine. J Pharmacol Exp Ther 324:416-421.

Salvatore CA, Moore EL, Calamari A, Cook JJ, Michener MS, O’Malley S, Miller PJ, Sur C, Williams DL Jr., Zeng Z, et al. (2010) Pharmacological properties of MK3207 , a potent and orally active calcitonin gene-related peptide receptor antagonist. J Pharmacol Exp Ther 333:152-160.

Serrano D, Buse DC, Manack Adams A, Reed ML, and Lipton RB (2015) Acute treatment optimization in episodic and chronic migraine: results of the American Migraine Prevalence and Prevention (AMPP) Study. Headache 55:502-518.

Stauffer VL, Dodick DW, Zhang Q, Carter JN, Ailani J, and Conley RR (2018) Evaluation of galcanezumab for the prevention of episodic migraine: the EVOLVE1 randomized clinical trial [published correction appears in JAMA Neurol (2019) 76:872]. JAMA Neurol 75:1080-1088.

Steiner TJ, Stovner LJ, Vos T, Jensen R, and Katsarava Z (2018) Migraine is first cause of disability in under 50s: will health politicians now take notice? J Headache Pain 19:17.

Suessbrich H, Waldegger S, Lang F, and Busch AE (1996) Blockade of HERG channels expressed in Xenopus oocytes by the histamine receptor antagonists terfenadine and astemizole. FEBS Lett 385:77-80.

Tepper S, Ashina M, Reuter U, Brandes JL, Doležil D, Silberstein S, Winner P, Leonardi D, Mikol D, and Lenz R (2017) Safety and efficacy of erenumab for preventive treatment of chronic migraine: a randomised, double-blind, placebocontrolled phase 2 trial. Lancet Neurol 16:425-434

Thorlund K, Sun-Edelstein C, Druyts E, Kanters S, Ebrahim S, Bhambri R, Ramos E, Mills EJ, Lanteri-Minet M, and Tepper S (2016) Risk of medication overuse headache across classes of treatments for acute migraine. $J$ Headache Pain 17:107. Ubrelvy. Package insert. Allergan plc, Madison, NJ. (2019).

Voss T, Lipton RB, Dodick DW, Dupre N, Ge JY, Bachman R, Assaid C, Aurora SK and Michelson D (2016) A phase IIb randomized, double-blind, placebo-controlled trial of ubrogepant for the acute treatment of migraine Cephalaloia 36:887-898.

Vu T, Ma P, Chen JS, de Hoon J, Van Hecken A, Yan L, Wu LS, Hamilton L, and Vargas G (2017) Pharmacokinetic-pharmacodynamic relationship of erenumab (AMG 334) and capsaicin-induced dermal blood flow in healthy and migraine subjects. Pharm Res 34:1784-1795.

Walker CS, Eftekhari S, Bower RL, Wilderman A, Insel PA, Edvinsson L, Waldvogel HJ, Jamaluddin MA, Russo AF, and Hay DL (2015) A second trigeminal CGRP receptor: function and expression of the $\mathrm{AMY}_{1}$ receptor. Ann Clin Transl Neurol 2. Wang J, Della Penna K, Wang H, Karczewski J, Connolly TM, Koblan KS, Bennett PB, and Salata JJ (2003) Functional and pharmacological properties of canine ERG potassium channels. Am J Physiol Heart Circ Physiol 284:H256-H267.

Yasuda N, Cleator E, Kosjek B, Yin J, Xiang B, Chen F, Kuo S, Belyk K, Mullens PR, Goodyear A, et al. (2017) Practical asymmetric synthesis of a calcitonin gene-related peptide (CGRP) receptor antagonist ubrogepant. Org Process Res Dev 21:1851-1858.

D.H.E. 45. Dihydroergotamine mesylate injection, solution [package insert]. Valeant Pharmaceuticals North America, Costa Mesa, CA. (2002)

Emgality. Package insert. Eli Lilly and Company, Indianapolis, IN. (2018)

Address correspondence to: Dr. Pradeep Banerjee, Allergan plc, 5 Giralda Farms, Madison, NJ 07940. E-mail: Pradeep.Banerjee@Allergan.com 